Journal of Patient-Centered çAdvocateAuroraHealth

Research and Reviews

Volume 4

Issue 4 - Health Disparities and Inequities: Part

Article 5 I

$11-6-2017$

\title{
Health Care Disparities Knowledge, Attitudes, and Behaviors in Resident Physicians
}

\author{
Rebecca Hammarlund \\ Diana Hamer \\ Kathleen Crapanzano \\ Rachel Bernard \\ Carine Nzodom \\ Courtney James \\ Angie Johnson \\ Diane Kirby \\ Laura Hetzler \\ Chris Woodward \\ See next page for additional authors
}

Follow this and additional works at: https://aah.org/jpcrr

Part of the Health Services Research Commons, Medical Education Commons, and the Other Public Health Commons

\section{Recommended Citation}

Hammarlund R, Hamer D, Crapanzano K, Bernard R, Nzodom C, James C, Johnson A, Kirby D, Hetzler L, Woodward C, Sulzer J, Rabalais L, Calongne L. Health care disparities knowledge, attitudes, and behaviors in resident physicians. J Patient Cent Res Rev. 2017;4:230-6. doi: 10.17294/2330-0698.1450

Published quarterly by Midwest-based health system Advocate Aurora Health and indexed in PubMed Central, the Journal of Patient-Centered Research and Reviews (JPCRR) is an open access, peer-reviewed medical journal focused on disseminating scholarly works devoted to improving patient-centered care practices, health outcomes, and the patient experience. 


\section{Health Care Disparities Knowledge, Attitudes, and Behaviors in Resident Physicians}

\section{Authors}

Rebecca Hammarlund, Diana Hamer, Kathleen Crapanzano, Rachel Bernard, Carine Nzodom, Courtney James, Angie Johnson, Diane Kirby, Laura Hetzler, Chris Woodward, Jesse Sulzer, Lauren Rabalais, and Laurinda Calongne 


\title{
Health Care Disparities Knowledge, Attitudes, and Behaviors in Resident Physicians
}

\author{
Rebecca Hammarlund, PhD, 1,2 Diana Hamer, PhD,, Kathleen Crapanzano, MD, ,,2 Rachel Bernard, \\ DO,,$^{1,3}$ Carine Nzodom, MD, ${ }^{1,2}$ Courtney James, MD, ${ }^{1,3}$ Angie Johnson, MD, ${ }^{2}$ Diane Kirby, MD, ${ }^{1,3}$ \\ Laura Hetzler, MD, ${ }^{2}$ Chris Woodward, DO ${ }^{2}$ Jesse Sulzer, MD, PhD,${ }^{2}$ Lauren Rabalais, MPA, ${ }^{1}$ \\ Laurinda Calongne, EdD ${ }^{1}$ \\ ${ }^{1}$ Our Lady of the Lake Regional Medical Center, Baton Rouge, LA; ${ }^{2}$ Louisiana State University Health Sciences Center \\ New Orleans, New Orleans, LA; ${ }^{3}$ Our Lady of the Lake Children's Hospital, Baton Rouge, LA
}

Purpose $\quad$ Health care disparities are an important but sometimes underrepresented topic in graduate medical
education. In this study we measured the impact of educational and behavioral interventions on
resident knowledge about and attitudes toward health care disparities.

Methods Faculty from 6 residency programs designed and presented an hour-long educational intervention to emphasize the importance of and increase resident knowledge about health care disparities. Selected residents then helped design a month-long behavioral intervention to engage their peers in conversations about disparities with patients. Surveys were administered pre- and post-educational intervention as well as post-behavioral intervention in order to measure the impact each intervention had on resident knowledge and attitudes.

Results Paired-samples t-tests showed that residents were more knowledgeable about health care disparities issues following didactic teaching $(P<0.001)$ and felt such issues were more important $(P<0.001)$. Furthermore, presence of these feelings significantly predicted the frequency of engaging in the behavioral intervention $(r=0.44, P<0.01)$.

Conclusions Two brief, simple interventions produced significant changes in resident knowledge, attitudes and behaviors regarding health care disparities. The educational intervention was most effective at increasing knowledge of disparities in general and encouraging participation in the behavioral intervention, while the behavioral intervention was useful in increasing knowledge of specific patients' barriers to care. (J Patient Cent Res Rev. 2017;4:230-236.)

Keywords health care disparities, graduate medical education, knowledge, attitudes

$\mathrm{R}$ esearch has demonstrated the existence of wide disparities in health care in the United States, ${ }^{1}$ which are predominantly based on socioeconomic factors ${ }^{2,3}$ and have large effects on morbidity and mortality for a variety of conditions. ${ }^{4}$ Although these disparities are common knowledge, methods for ameliorating them are still under development. ${ }^{5-7}$

Correspondence: Rebecca Hammarlund, PhD, LSU-OLOL Psychiatry Residency Program, 5246 Brittany Drive, Office 335, Baton Rouge, LA, 70808, T: +1-225-757-4218, Email: Rebecca.Horn@fmolhs.org
Resident physicians are typically at the forefront of delivering care to patients in underserved communities but are often limited in their preparedness to deal with health care disparities because of their clinical responsibilities, time constraints and cultural differences between themselves and their patients. ${ }^{8,9}$ Thus, educational institutions have worked to integrate educational interventions on disparities into regular graduate medical education (GME). ${ }^{10-13}$ While these interventions reported gains in resident knowledge, they have not been universally adopted nor optimized for diverse settings. 
The current study was conducted by a multidisciplinary team composed of GME leadership, researchers, faculty and residents from 6 residency programs as part of the Alliance of Independent Academic Medical Centers' National Initiative $V$ on health care disparities. The study was designed to assess the individual and combined impact of two types of intervention - an educational intervention led by faculty and a behavioral intervention driven by residents - on resident physicians' knowledge, attitudes and behaviors regarding health care disparities. Although previous interventions have demonstrated positive impacts on residents' understanding of and attitudes toward health care disparities, few have utilized or compared multiple types of interventions nor have they focused on residents as drivers of change.

\section{METHODS}

This project was approved by the institutional review boards of both Louisiana State University Health Sciences Center New Orleans (New Orleans, LA) and Our Lady of the Lake College (Baton Rouge, LA). The first phase of the intervention was an educational didactic session intended to provide relevant disparities-related information about the city and state surrounding the medical center and outpatient clinics in which the resident physicians provide patient care. The second phase of the intervention was behavioral in nature and was designed to engage residents as data gatherers by encouraging them to initiate conversations with patients about potential barriers to care.

Going into the project, we had several hypotheses about the effects of our interventions. First, we hypothesized that residents who were more informed about health care disparities would believe health care disparities topics were more relevant to their practice. Next, we hypothesized that residents who believed these topics were relevant would be more likely to engage their patients in discussion about potential barriers to care. From there, we hypothesized that residents who engaged with their patients about barriers would be more likely to have new insights into their patients' lives and health needs, and that this new insight would spur further changes in their attitudes toward their patients.

\section{Participants}

Participation in the didactic session was open to all residents $(\mathrm{N}=160)$ in 6 residency programs: emergency medicine (EM), internal medicine (IM), pediatrics
(Peds), psychiatry (Psy), general surgery (Sur), and otolaryngology (ENT). Participation in the behavioral intervention was limited to residents who were working outpatient clinic rotations $(n=130)$. For EM, IM, Peds, Sur and ENT, this subset included residents from all postgraduate years (PGY). In Psy, only PGY3 and PGY-4 residents $(n=9)$ work in the outpatient clinic. The outpatient setting was selected because the team felt outpatient care is more susceptible to barriers such as transportation and co-pay difficulties than the inpatient setting. Participants provided anonymous code information to match pre-, mid- and postintervention survey responses.

\section{Didactic Intervention, Preintervention Survey}

A 1-hour didactic session was developed and delivered by faculty members from IM, EM, Peds and Psy. The session covered general facts about health care disparities but focused on providing residents with information about specific issues faced by people in the Baton Rouge area. Public health data maps, Google Street View images and other visual aids were incorporated into the presentation to help residents visualize the local barriers to health care, and a fictional case report was created to tie together all of the information presented. To ensure higher attendance rates, the 4 faculty members presented the didactic session during residents' protected education times for each of the 6 programs.

Prior to the didactic session, researchers handed out a survey consisting of basic demographic items, objective knowledge items that were modified slightly from those used by Weiland et al. ${ }^{9}$ to reflect more current or more community-specific facts, and subjective judgment items from the same source. ${ }^{9}$ More information regarding the predidactic survey is shown in Table 1.

\section{Post-Didactic Intervention Survey, Question Development}

One month after the didactic session, researchers sent participating residents a link to the online post-didactic intervention survey. This survey contained 5 yes/no questions, a subset of subjective judgment items from the predidactic survey and a subset of Baton Rouge disparities items from the predidactic survey (Table 1). Subsets of subjective judgment and disparities items were selected in lieu of repeating the entire predidactic survey because researchers felt that including too 
Table 1. Items on Pre-, Mid-, and Postintervention Surveys

\begin{tabular}{|c|c|c|c|}
\hline Item type & $\begin{array}{l}\text { Pre-didactic } \\
\text { intervention }\end{array}$ & $\begin{array}{l}\text { Post-didactic } \\
\text { intervention }\end{array}$ & \begin{tabular}{|l|} 
Post-behavioral \\
intervention (final) \\
\end{tabular} \\
\hline Match information & Anonymous code & Anonymous code & Anonymous code \\
\hline Personal information & $\begin{array}{l}\text { Sex, program, parental } \\
\text { income, parental education }\end{array}$ & - & - \\
\hline Objective knowledge & $\begin{array}{l}\text { General disparities } \\
\left(11 \text { items }^{*}\right) \\
\text { Baton Rouge disparities } \\
(8 \text { items })\end{array}$ & $\begin{array}{l}\text { - } \\
\text { Baton Rouge disparities } \\
\text { (4 items) }\end{array}$ & $\begin{array}{l}- \\
-\end{array}$ \\
\hline Subjective judgment & $\begin{array}{l}\text { Importance of disparities } \\
\left(13 \text { items }{ }^{*}\right) \\
\text { Feelings of topic } \\
\text { knowledge }\left(13 \text { items }{ }^{*}\right)\end{array}$ & $\begin{array}{l}\text { Importance of disparities } \\
\left(5 \text { items }^{*}\right) \\
\text { Feelings of topic knowledge } \\
\left(5 \text { items }{ }^{*}\right)\end{array}$ & $\begin{array}{l}\text { Importance of disparities } \\
\left(5 \text { items }^{*}\right) \\
\text { Feelings of topic } \\
\text { knowledge }\left(5 \text { items }{ }^{*}\right)\end{array}$ \\
\hline Yes/No items & $\begin{array}{l}- \\
- \\
- \\
- \\
- \\
-\end{array}$ & $\begin{array}{l}\text { 1. Did the didactic change } \\
\text { behavior? } \\
\text { 2. Do you ask about } \\
\text { disparities now? } \\
\text { 3. Do you make different } \\
\text { recommendations now? } \\
\text { 4. Do you know patients } \\
\text { better now? } \\
\text { 5. Have you done your own } \\
\text { research? } \\
\text { - }\end{array}$ & $\begin{array}{l}\text { - } \\
\text { - } \\
\text { 1. Do you know patients } \\
\text { better now? } \\
\text { - } \\
\text { 2. Do you see patients } \\
\text { differently? }\end{array}$ \\
\hline Multiple choice & - & - & $\begin{array}{l}\text { 3. How many patients } \\
\text { did you ask per week? }\end{array}$ \\
\hline Patient response summary & - & - & $\begin{array}{l}\text { 4. Rank barriers by } \\
\text { frequency from } 1 \text { to } 8 \text {. }\end{array}$ \\
\hline
\end{tabular}

${ }^{*}$ Items from Weiland et al. ${ }^{9}$

many items would negatively affect participation rates. Included items were chosen because they most closely aligned with information presented during the didactic session and thus were more likely to capture changes in attitudes and knowledge resulting from the education than nonselected items. The postdidactic survey was available for completion for 2 weeks.

\section{Behavioral Intervention and Final Survey}

Resident champions from each of the 6 programs met with each other, with faculty and with researchers during the postdidactic survey data collection period in order to develop program-specific disparities questions to be utilized during the behavioral intervention. Once the data collection window closed, faculty and resident champions introduced all other residents to the behavioral intervention. Residents were instructed to ask program-specific disparities-related questions of their clinic patients for one full month.

Several methods were used to remind residents to ask the questions. These methods included: twice-weekly text message reminders, pocket cards, reminder signs on computers, and a smart phrase that could be added to the medical note template. The smart phrase also provided residents a place to record responses if they chose to.

After the month had passed, researchers distributed the final survey. This survey contained the subset of subjective judgment items from the previous surveys, 2 yes/no items, 1 multiple choice item, 1 ranking item (Table 1), and 2 open-ended items asking residents to 
describe the most and least surprising barriers cited by patients. We did not include objective knowledge items on the final survey because the behavioral intervention was about communicating with specific patients, not learning factual information (as in the didactic interventions), hence there was no reason to expect scores to have changed on these items.

\section{Discussion Groups}

Selected residents who had participated in the intervention were invited to participate in discussion groups to provide feedback on the project. Groups were led by a party not associated with the project while two researchers transcribed the discussion, with care to anonymize all comments.

\section{RESULTS}

\section{Participants}

The predidactic survey (time point 1 , or T1) was completed by 114 of 160 individuals, the postdidactic survey (T2) by 107 of 160 individuals and the final survey (T3) by 92 of 130 individuals. Despite this response rate, data for only 38 individuals were able to be matched across all three time points using the anonymous code (see Discussion for details). Therefore, results reported herein refer only to this matchable subset, though it should be noted that, when performing group comparisons on the larger sample, results were similar to the within-subjects comparisons on the subset.

There were 7 EM, 10 IM, 15 Peds, 3 Psyc, 2 Sur and 1 ENT resident in the matchable subset. Of these 38 residents, 25 were male and 13 female. Median parental income was $\$ 80,000$ to $\$ 100,000$, and $77 \%$ reported that their parents had college degrees $(37 \%$ 4-year degrees, $40 \%$ graduate/professional degrees).

\section{Objective Knowledge}

At T1, participants correctly answered an average of $45.4 \%$ (standard deviation [SD]: 15.45) of objective knowledge items. Broken down by knowledge type, mean percentage correct was $48.1 \%$ (SD: 18.29) for general disparities and 41.8\% (SD: 17.98) for Baton Rouge disparities.

Only a subset of Baton Rouge disparities items were repeated at T2. A paired-samples t-test showed that participants correctly answered significantly more repeated Baton Rouge disparities items at T2 (mean: 27\%, SD: 27.5) than at T1 (mean: $16.4 \%$, SD: 17.7); $t(37)=-2.46, \mathrm{P}<0.05$.

\section{Subjective Knowledge and Importance}

Figure 1 displays the mean ratings for subjective knowledge items at all three time points. Pairedsamples t-tests showed residents rated their knowledge higher at $\mathrm{T} 2$ than at $\mathrm{T} 1(t[37]=-3.19, \mathrm{P}<0.01)$ and higher at $\mathrm{T} 3$ than $\mathrm{T} 1(t[37]=-3.06, \mathrm{P}<0.01)$. There was no significant difference between $\mathrm{T} 2$ and $\mathrm{T} 3$.

Figure 1 also displays the mean ratings for subjective importance items at all three time points. Pairedsamples t-tests showed that residents rated importance higher at $\mathrm{T} 2$ than at $\mathrm{T} 1(t[33]=-3.00, \mathrm{P}<0.01)$. There was no significant difference between $\mathrm{T} 1$ and $\mathrm{T} 3$ nor between $\mathrm{T} 2$ and $\mathrm{T} 3$.

\section{Behavioral Questions}

At T2, 57.1\% of residents agreed that the didactic intervention had changed their behavior, with 52.8\% indicating they asked patients about barriers more often and $65.7 \%$ indicating they had made new care recommendations with barriers in mind. Furthermore, 91.7\% agreed they knew more about their patients after the didactic intervention. However, only $6.1 \%$ reported having done any independent research on health care barriers.

At T3, 71.5\% of residents agreed they knew more about their patients after the behavioral intervention; $28.6 \%$ reported having new attitudes toward their patients. In terms of behavior, $10.5 \%$ stated they never asked patients the barriers questions and $60.5 \%$ reported asking 5 or fewer patients per week. In contrast, $13.2 \%$ reported asking all patients the questions. The remaining $15.8 \%$ reported asking 6 or more patients the questions each week.

\section{Follow-Up Items}

In the final survey (T3), $63.9 \%$ of residents agreed they needed more information on disparities. More than half (55.6\%) said they would like this information to be provided via email or other online sources. Residents also indicated that the three most frequently reported patient barriers were: Transportation, Lack of Money for Co-pays, and Lack of Insurance. 


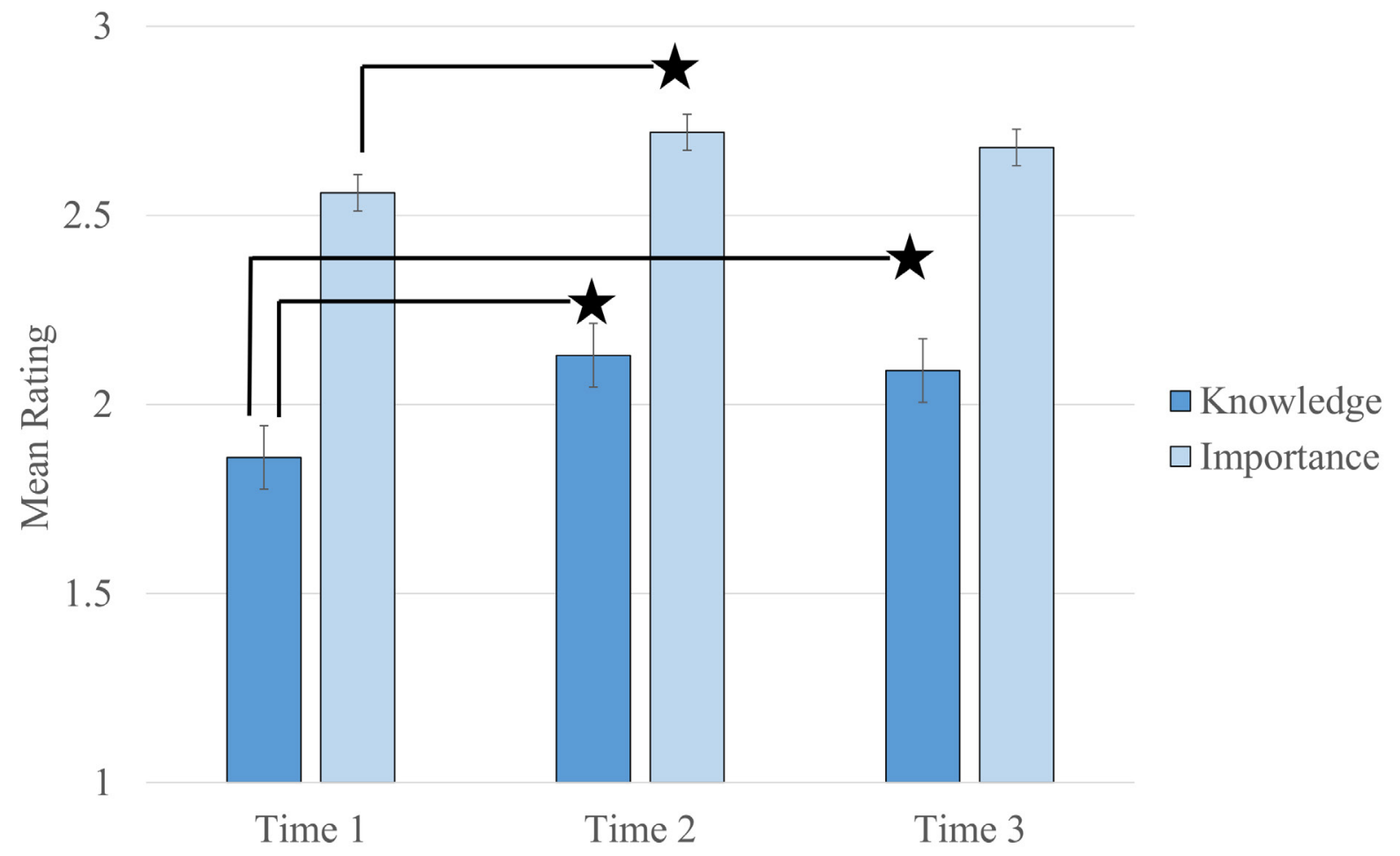

Figure 1. Mean ratings for subjective knowledge and subjective importance items from Weiland et al for time points 1, 2 and 3. Values on the $y$-axis range from 1 (not at all knowledgeable/important) to 3 (very knowledgeable/ important). Star indicates a statistically significant difference between values.

\section{Attitudes and Behaviors}

The degree of change in subjective knowledge ratings between $\mathrm{T} 1$ and $\mathrm{T} 2$ correlated significantly both with the degree of change in subjective importance ratings $(\mathrm{r}=0.59, \mathrm{P}<0.001)$ and directly with $\mathrm{T} 2$ subjective importance ratings $(\mathrm{r}=0.49, \mathrm{P}<0.01)$. In other words, the more that residents felt they learned from the didactic intervention, the more important they subsequently rated health care disparities issues.

Reporting that disparities issues were important after the didactic intervention was significantly correlated with asking more patients about barriers during the behavioral intervention ( $\mathrm{r}=0.44, \mathrm{P}<0.01)$; however, subjective importance ratings at $\mathrm{T} 1$ and $\mathrm{T} 3$ were not related to behavior. Residents who reported asking patients the questions more often also reported feeling they knew more about their patients $(\mathrm{r}=0.42, \mathrm{P}<0.05)$. Residents who reported feeling they knew more about their patients from asking questions also reported changed attitudes toward patients $(\mathrm{r}=0.44, \mathrm{P}<0.01)$.

\section{Open-Ended Responses, Discussion Groups}

Response rates for open-ended survey items were not high, though the responses followed themes similar to those that arose during discussion groups. Given the limited data, more formal qualitative analysis was not warranted. However, it was noted that residents seemed to fall into two camps: those who were motivated by the didactic and behavioral interventions, and those who were frustrated by them. In the motivated camp, we heard from residents who were inspired to do their own follow-up research and engage in more "aggressive" (their word) utilization of resources such as social workers. In the frustrated camp were those who felt their patients did not welcome the discussion of barriers and those who felt that the discussion was useless, either because they already knew what patients' barriers were or because they felt unable to provide help or advice about how to overcome those barriers anyway.

\section{DISCUSSION}

Disparities in health care have a tremendous impact on morbidity and mortality in patients across specialties, ${ }^{1}$ yet our preintervention data showed a large deficit in resident knowledge of community-specific disparities, a shortcoming also identified in other studies. ${ }^{8,10}$ 
Previously published interventions utilized educational interventions lasting between three ${ }^{12}$ and four ${ }^{11}$ hours or that were based on somewhat complex experiential learning models. ${ }^{13}$ Our study attempted to address the knowledge deficit with a 1-hour didactic session and a brief behavioral intervention that could easily be incorporated into every patient encounter.

Despite the brevity and simplicity of our interventions, we nevertheless saw increased resident knowledge regarding health care disparities. This increased knowledge was associated with greater reported recognition of disparities as important, which in turn was related to increased participation in the brief behavioral intervention. These results, in addition to being consistent with literature that links attitude change to behavioral change, ${ }^{14}$ suggest that interventions in this area need not be overly time-consuming or complex to effect real change in residents.

Beyond simple intervention effects, the purpose of including two types of intervention in the current study was to examine if either was more effective than the other or if the two produced a cumulative effect. Our results showed that the didactic was effective in changing general knowledge and attitudes about disparities that were measured by the subjective judgment items, ${ }^{9}$ whereas the behavioral intervention was associated with feelings of increased knowledge and new attitudes about residents' specific patients. In general, then, we would argue our results show distinct cumulative effects of our interventions. First, the didactic session informed residents about disparities in the community and helped residents see their importance. Next, these changes led residents to engage more often in the behavioral intervention, which itself resulted in more knowledge about and different attitudes toward residents' own patients.

\section{Limitations}

While this study produced promising and informative results, several issues arose that prevented the evidence presented here from being stronger. The first involved the anonymous coding scheme. Information collected to create the anonymous code was nonchanging and thus should have been easily reportable, yet it was unexpectedly difficult to get large numbers of residents to provide identical information at separate time points. Results may be more compelling if we had been able to match more than 38 residents across all three time points, as individual changes were what we most hoped to capture. That said, while we did not report data from individuals who matched at only two time points, those results were in line with the reported data, though the effects were smaller. This fact suggests an alternative explanation for the effect of the interventions: It may be that those individuals who are conscientious or engaged enough to provide the correct code information three times are also more prone to appreciate and apply information related to health care disparities. In other words, it is possible that individual difference factors not accounted for in the study influenced the effectiveness of our interventions. This is an interesting possibility for future research.

A second limitation to our study is that we had to be selective as to which items were presented for repeat measurement in order not to discourage participation with an onerously long survey. Though the data would have been stronger with more complete overlap in measurement tools, we felt this trade-off was both necessary and appropriate.

Another issue involved the timing of the interventions. Given the project timeline, the behavioral intervention occurred near the end of an academic year when many residents were graduating or transitioning to fellowships. Ideally health care disparities information would be integrated into didactics throughout the academic year, and any sort of behavioral intervention like that used in this study would begin at the start of the intern year and be reinforced throughout the residency training program.

Incorporating disparities interventions throughout the academic year also would address our next issue, which was that some residents seemed to feel that asking their patients about barriers to care was awkward or unwelcomed by the patients. Incorporating health care disparities information and behavioral directives, such as those used in our intervention, throughout residency training would likely go a long way toward making residents more comfortable discussing these issues with patients, which in turn may make the discussions with patients more natural and comfortable for both parties.

Finally, some residents expressed frustration that they did not have more information on community resources available to combat disparities. Other 
residents took it upon themselves to research such resources. Given this variability in motivation and ability to seek out information on resources, it should fall on educational institutions and medical centers to make such information readily available. Indeed, if progress in ameliorating disparities is to be made, this information's availability should extend beyond residents to other physicians in the organization.

Despite these and other limitations in our study, including several barriers (ie, timing, awkwardness, lack of resource information) to discussions about barriers to care, our residents still demonstrated and self-reported changes in their knowledge and attitudes. Thus, it seems likely that removal of these barriers would only increase the strength of our findings.

\section{CONCLUSIONS}

Our results demonstrate the effectiveness of a didactic intervention in increasing resident knowledge of health care disparities. This knowledge increase can affect a resident's feelings about the importance of these topics, which may subsequently lead to behavioral changes in medical practice. These behavioral changes may make a vital difference in the treatment of patients who are facing barriers to care by alerting the physician to the existence of those barriers and introducing an opportunity to find ways to address them.

\section{Patient-Friendly Recap}

- Though at the forefront of delivering care to patients in underserved communities, resident physicians often are ill-prepared to deal with health care disparities.

- The authors tested whether educational and behavioral interventions provoked change in residents' disparity-related knowledge, attitudes and behaviors.

- They found that residents not only grew more knowledgeable about local disparities following the sessions, but also placed more importance on such issues.

- Changing behavioral patterns of resident physicians could improve health care disparities by introducing opportunities to identify and address barriers to care.

\section{Conflicts of Interest}

None.

\section{References}

1. Committee on Understanding and Eliminating Racial and Ethnic Disparities in Health Care. Introduction and literature review. In: Smedly BD, Stith AY, Nelson AR (eds). Unequal Treatment: Confronting Racial and Ethnic Disparities in Health Care. Washington, DC: National Academy Press, 2003, pp. 29-78.

2. Hayward MD, Miles TP, Crimmins EM, Yu Y. The significance of socioeconomic status in explaining the racial gap in chronic health conditions. Am Sociol Rev. 2000;65:910-30. CrossRef

3. Williams DR, Collins C. US socioeconomic and racial differences in health: patterns and explanations. Annu Rev Sociol. 1995;21:349-86. CrossRef

4. Kapral MK, Wang H, Mamdani M, Tu JV. Effect of socioeconomic status on treatment and mortality after stroke. Stroke. 2002;33:268-75. CrossRef

5. Umbdenstock R, Lofton KE. Hospitals must take the lead in eliminating disparities in care. http://www.aha.org/ content/00-10/09elimdisp-essentials.pdf. Accessed April 20, 2017.

6. Jackson CS, Gracia JN. Addressing health and health-care disparities: the role of a diverse workforce and the social determinants of health. Public Health Rep. 2014;129 Suppl 2:57-61. CrossRef

7. Centers for Disease Control and Prevention. Strategies for reducing health disparities. Updated October 3, 2016. https:// www.cdc.gov/minorityhealth/strategies2016/. Accessed April 20, 2017.

8. Weissman JS, Betancourt J, Campbell EG, et al. Resident physicians' preparedness to provide cross-culture care. JAMA. 2005;294:1058-67. CrossRef

9. Weiland ML, Beckman TJ, Cha SS, Beebe TJ, McDonald FS; Underserved Care Curriculum Collaborative. Resident physicians' knowledge of underserved patients: a multiinstitutional survey. Mayo Clin Proc. 2010;85:728-33. CrossRef

10. Beach MC, Price EG, Gary TL, et al. Cultural competency: a systematic review of health care provider educational interventions. Med Care. 2005;43:356-73.

11. Khanna SK, Cheyney M, Engle M. Cultural competency in health care: evaluating the outcomes of a cultural competency training among health care professionals. J Natl Med Assoc. 2009;101:886-92. CrossRef

12. McDougle L, Ukockis G, Adamshick L. Evaluation of a new cultural competency training program: CARE Columbus. J Natl Med Assoc. 2010;102:756-60. CrossRef

13. Patow C, Bryan D, Johnson G, et al. Who's in our neighborhood? Healthcare disparities experiential education for residents. Ochsner J. 2016;16:41-4.

14. Schuman H, Johnson MP. Attitudes and behavior. Annu Rev Sociol. 1976;2:161-207. CrossRef

(C) 2017 Aurora Health Care, Inc. 